\title{
Theranostics in nuclear medicine practice
}

This article was published in the following Dove Press journal:

OncoTargets and Therapy

3 October 2017

Number of times this article has been viewed

\author{
Anna Yordanova' \\ Elisabeth Eppard ${ }^{2}$ \\ Stefan Kürpig ${ }^{2}$ \\ Ralph A Bundschuh ${ }^{3}$ \\ Stefan Schönberger ${ }^{4}$ \\ Maria Gonzalez-Carmona ${ }^{5}$ \\ Georg Feldmann ${ }^{6}$ \\ Hojjat Ahmadzadehfar' \\ Markus Essler' \\ 'Department of Nuclear Medicine \\ (Clinical Nuclear Medicine), \\ ${ }^{2}$ Department of Nuclear Medicine \\ (Radiochemistry), ${ }^{3}$ Department \\ of Nuclear Medicine (Medical \\ Physics and PET), ${ }^{4}$ Department \\ of Paediatric Haematology and \\ Oncology, ${ }^{5}$ Department of Medicine I, \\ ${ }^{6}$ Department of Medicine 3, University \\ Hospital Bonn, Bonn, Germany
}

Correspondence: Anna Yordanova Department of Nuclear Medicine, University Hospital Bonn, Sigmund-FreudStr 25, Bonn 53127, Germany

$\mathrm{Tel}+49228287$ I $68 \mid 4$

Fax +492282879019107

Email anna.yordanova@ukbonn.de
Abstract: The importance of personalized medicine has been growing, mainly due to a more urgent need to avoid unnecessary and expensive treatments. In nuclear medicine, the theranostic approach is an established tool for specific molecular targeting, both for diagnostics and therapy. The visualization of potential targets can help predict if a patient will benefit from a particular treatment. Thanks to the quick development of radiopharmaceuticals and diagnostic techniques, the use of theranostic agents has been continually increasing. In this article, important milestones of nuclear therapies and diagnostics in the context of theranostics are highlighted. It begins with a well-known radioiodine therapy in patients with thyroid cancer and then progresses through various approaches for the treatment of advanced cancer with targeted therapies. The aim of this review was to provide a summary of background knowledge and current applications, and to identify the advantages of targeted therapies and imaging in nuclear medicine practices.

Keywords: theranostics, nuclear medicine, personalized medicine, PET/CT, therapy, diagnostics

\section{Introduction: goals of theranostics in nuclear medicine}

Challenges in modern oncology include the fact that patients are getting older and are typically unfit for conventional chemotherapy regimens because of comorbidities or poor performance status. ${ }^{1}$ Furthermore, the occurrence of side effects may aggravate treatment compliance in both young and elderly patients. ${ }^{2}$ To manage these problems, it is important to improve patient selection, reduce side effects, and enhance therapeutic efficacy. Taking these factors into consideration, the combination of targeted cancer imaging and therapy is a considerable achievement for personalized medicine.

The theranostic approach in nuclear medicine couples diagnostic imaging and therapy using the same molecule or at least very similar molecules (Figure 1), which are either radiolabeled differently or given in different dosages. For example, iodine-131 and lutetium-177 are gamma and beta emitters; thus, these agents can be used for both imaging and therapy. Furthermore, different isotopes of the same element, for example, iodine-123 (gamma emitter) and iodine-131 (gamma and beta emitters), can also be used for theranostic purposes ${ }^{3,4}$ Newer examples are yttrium-86/yttrium-90 or terbium isotopes $(\mathrm{Tb}):{ }^{152} \mathrm{~Tb}$ (beta plus emitter), ${ }^{155} \mathrm{~Tb}$ (gamma emitter), ${ }^{149} \mathrm{~Tb}$ (alpha emitter), and ${ }^{161} \mathrm{~Tb}$ (beta minus particle). ${ }^{5,6}$

The detection of potential targets can help predict whether a patient will benefit from a particular treatment. Theranostics can be useful for estimating the potential response and eventual toxicity. During the treatment, theranostics can be applied in monitoring the therapy course. However, one cause of concern is the safety of high cumulative doses of radioactive agents after multiple repeated cycles. For instance, reports concerning irreversible high-grade toxicity followed soon after the first treatments with radioiodine (iodine-131). ${ }^{7}$ However, there have been remarkable advances in nuclear 


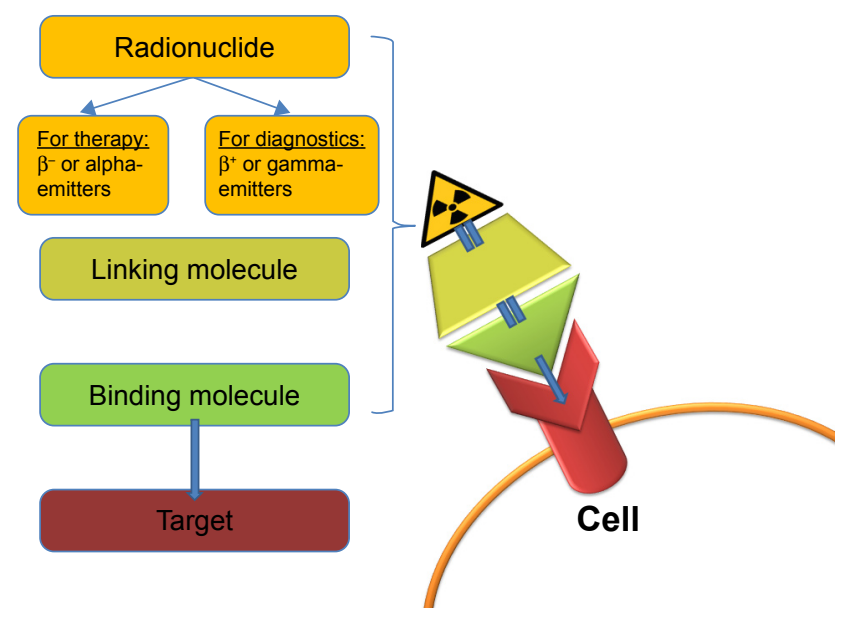

Figure I The theranostic principle in nuclear medicine involves combining diagnostic imaging and therapy with the same molecule, which is radiolabeled differently, or administered in other dosages. In case of radioiodine therapy (RAI), the radioisotope $\left({ }^{131} \mathrm{I}\right.$ or $\left.{ }^{123} \mathrm{I}\right)$ can be directly mediated by the sodium-iodide symporter in the thyroid cells. In other cases, it can be more complex. The image shows a simplified model of a radiopharmaceutical, which consists of a binding molecule that binds the target, and a linking molecule, which binds the radioisotope. Examples of such theranostic molecules are DOTA-TOC, DOTA-TATE, and PSMA-6I7.

medicine, especially in the field of targeted therapies. After a proper preselection of candidates, targeted nuclear therapies have proven to be effective in the majority of cases with a favorable safety profile. ${ }^{8-11}$ Recent studies have shown no evidence of grade $3 / 4$ toxicity in patients with neuroendocrine tumors after repeated ( $\geq 8$ cycles) radiopeptide therapy with a cumulative dose of up to $97 \mathrm{GBq} .{ }^{12}$ Good tolerability has also been observed in patients with prostate cancer (PC) after a cumulative dose of $36 \mathrm{GBq}$ and up to six cycles of radioligand therapy. ${ }^{13,14}$

Nuclear imaging utilizes gamma and positron emitters $\left(\beta^{+}\right)$. Gamma emitters, such as technetium-99m ( $\left.{ }^{99 \mathrm{~m}} \mathrm{Tc}\right)$ or iodine-123 ( $\left.{ }^{123} \mathrm{I}\right)$, can be located using gamma cameras (planar imaging) or SPECT (single photon emission computed tomography). ${ }^{15}$ However, better resolution can be achieved via PET (positron emission tomography) using positron emitters, such as gallium-68 $\left({ }^{68} \mathrm{Ga}\right)$ and fluor-18 $\left({ }^{18} \mathrm{~F}\right) .{ }^{16}$

Most therapeutic radiopharmaceuticals are labeled with beta-emitting isotopes $\left(\beta^{-}\right)$. The tissue penetration of these particles is proportional to the energy of the radioisotopes. ${ }^{17}$ Beta particles have a potential cytocidal effect, but they also spare the surrounding healthy tissue due to having a tissue penetration of only a few millimeters. ${ }^{8}$ Commonly used beta emitters in routine nuclear oncology practices include lutetium-177 ( ${ }^{177} \mathrm{Lu}$, tissue penetration: 0.5-0.6 mm, maximum: $2 \mathrm{~mm}, 497 \mathrm{keV}$, half-life: 6.7 days) and yttrium-90 $\left({ }^{90} \mathrm{Y}\right.$, tissue penetration: mean $2.5 \mathrm{~mm}$, maximum: $11 \mathrm{~mm}$, $935 \mathrm{keV}$, half-life: 64 hours). ${ }^{8,10,13,18-20}$
The first theranostic radiopharmaceutical in nuclear medicine history was radioiodine, which was used for therapy and imaging in thyroid diseases. ${ }^{21}$ Since then, the use of theranostic agents has been consistently increasing. Nuclear targeted therapies play an essential role, especially in patients with advanced neuroendocrine tumors, such as gastroenteropancreatic (GEP) tumors, bronchopulmonary neuroendocrine tumors, pheochromocytoma, and neuroblastoma. ${ }^{10,11,20,22-27}$ Furthermore, there are positive results with radioligand therapies in metastatic PC and metastatic melanoma. ${ }^{8,13,19,28,29}$

The aim of this review was to discuss the most important milestones of nuclear theranostics in current practice (Table 1), and to provide a summarized background and overview of current applications and advantages of targeted therapies and imaging.

\section{Radioiodine therapy: "the gold standard" in thyroid diseases}

Iodine (stable isotope: iodine-127) is taken up by the thyroid gland for the production of thyroid hormones, namely, thyroxine (T4) and triiodothyronine (T3). ${ }^{30}$ Thyroid hormones are vital for the embryonic and neonatal development of the brain, normal growth, and metabolic balance..$^{9,31-33}$ In 1936, Dr Saul Hertz, director of the Thyroid Clinic in Massachusetts (1931-1943), developed the idea of administering radioactive iodine in patients with thyroid diseases. Iodine and external beam radiation were well-known tools in thyroid disease therapy, but the combination of these was a considerably innovative approach. This idea followed a few years of preclinical studies in collaboration with the Massachusetts Institute of Technology (MIT), where the first cyclotron for medical use had been built. The MIT Cyclotron produced $90 \%$ iodine- $130\left({ }^{130} \mathrm{I}\right.$, half-life: 12 hours $)$ and $10 \%$ iodine- 131 ( ${ }^{131} \mathrm{I}$, half time: 8 days). Subsequently, on March 31, 1941, Dr Hertz treated the first patient with radioiodine $\left({ }^{130} \mathrm{I}\right) .{ }^{21,34,35}$

The first radioiodine therapy (RAI) with ${ }^{131} \mathrm{I}$ in patients with thyroid cancer (TC) was undertaken by Seidlin et al in 1946. ${ }^{36}$ This group studied the use of RAI in patients with metastatic thyroid carcinomas. ${ }^{36,37}$ Seidlin et al also reported one of the first cases of acute myeloid leukemia after repeated RAI treatments. ${ }^{7}$

To date, ${ }^{131} \mathrm{I}$ is still the gold standard for the therapy and diagnosis of differentiated TC. ${ }^{38}$ It is a low-cost nuclear reactor product from the neutron bombardment of tellurium131. ${ }^{131}$ I combines the characteristics of a beta $\left(\beta^{-}\right.$, approximately $90 \%$ of the radiation, mean: $192 \mathrm{keV}$, mean tissue penetration: $0.4 \mathrm{~mm}$ ) and gamma (approximately $10 \%$ of the radiation, mean: $383 \mathrm{keV}$ ) emitter. In this way, it irradiates 
Table I Overview of theranostic agents

\begin{tabular}{|c|c|c|c|c|c|}
\hline $\begin{array}{l}\text { Theranostic } \\
\text { molecule }\end{array}$ & lodine & mIBG & SSA & PSMA-ligands & $\begin{array}{l}\text { Benzamide/ } \\
\text { arylcarboxamide }\end{array}$ \\
\hline Target & Thyroid cancer cells & Neurosecretory granules & $\begin{array}{l}\text { SSTR, especially the } \\
\text { subtype SSTR2 }\end{array}$ & PSMA & Melanin \\
\hline $\begin{array}{l}\text { Planar imaging/ } \\
\text { SPECT or }\end{array}$ & ${ }^{131} \mid$ and ${ }^{123} \mid$ & {$\left[{ }^{|3|} \mid\right]\left|-\mathrm{mlBG},\left[{ }^{123} \mid\right]\right|-\mathrm{mlBG}$} & $\begin{array}{l}\text { SSA labeled with } \\
\text { indium-III }\end{array}$ & {$\left[{ }^{123} \mid\right] \mid-M I P-1072$} & {$\left[{ }^{123} \mid\right] \mid-B A 52$} \\
\hline PET & ${ }^{124} \mid$ & {$\left[{ }^{124} \mid\right]$ I-mIBG } & $\begin{array}{l}{\left[{ }^{68} \mathrm{Ga}\right] \mathrm{Ga}-D O T A-T A T E} \\
{\left[{ }^{68} \mathrm{Ga}\right] \mathrm{Ga}-D O T A-T O C} \\
{\left[{ }^{68} \mathrm{Ga}\right] \mathrm{Ga}-D O T A-N O C}\end{array}$ & $\begin{array}{l}{\left[{ }^{68} \mathrm{Ga}\right] \mathrm{Ga}-P S M A-I I} \\
{\left[{ }^{68} \mathrm{Ga}\right] \mathrm{Ga}-P S M A-6 I 7}\end{array}$ & {$\left[{ }^{18} \mathrm{~F}\right] \mathrm{F}-\mathrm{ICF} I 5002$} \\
\hline $\begin{array}{l}\text { Therapeutic } \\
\text { agent }\end{array}$ & $|31|$ & {$\left[{ }^{\mid 31} \mid\right] \mid-\mathrm{mlBG}$} & $\begin{array}{l}{\left[{ }^{177} \mathrm{Lu}\right] \mathrm{Lu}-\mathrm{DOTA} \text {-TATE }} \\
{\left[{ }^{177} \mathrm{Lu}\right] \mathrm{Lu}-\mathrm{DOTA} \text {-TOC }} \\
{\left[{ }^{90} \mathrm{Y}\right] \mathrm{Y} \text {-DOTA-TOC }} \\
{\left[{ }^{90} \mathrm{Y}\right] \mathrm{Y} \text {-DOTA-TATE }}\end{array}$ & $\begin{array}{l}{\left[{ }^{177} \mathrm{Lu}\right] \text { Lu-J59| }} \\
{\left[{ }^{90} \mathrm{Y}\right] \mathrm{Y}-J 591} \\
{\left[{ }^{131} 1\right] \mathrm{I}-\mathrm{MIP}-1095} \\
{\left[{ }^{177} \mathrm{Lu}\right] \text { Lu-PSMA-6I7 }}\end{array}$ & $\begin{array}{l}{\left[{ }^{131} \mid\right] \mid-B A 52} \\
{\left[{ }^{331} \mid\right]|-| C F \mid 5002}\end{array}$ \\
\hline Indication & Thyroid cancer & $\begin{array}{l}\text { Neuroblastomas, pheochromocytomas, } \\
\text { paragangliomas, medullary thyroid } \\
\text { carcinomas, and other NEN }\end{array}$ & $\begin{array}{l}\text { NEN, especially GEP- } \\
\text { NEN }\end{array}$ & $\begin{array}{l}\text { Metastatic prostate } \\
\text { cancer }\end{array}$ & $\begin{array}{l}\text { Metastatic } \\
\text { melanoma }\end{array}$ \\
\hline
\end{tabular}

Abbreviations: mIBG, metaiodobenzylguanidine; SSA, somatostatin analogs; SSTR, somatostatin receptors; NEN, neuroendocrine neoplasia; GEP, gastroenteropancreatic system; SPECT, single photon emission computed tomography; PET, positron emission tomography.

the TC and the thyroid remnant from the inside and, at the same time, targeted lesions can be visualized using a gamma camera or SPECT. ${ }^{9,32,33}$ Another radioisotope is ${ }^{123} \mathrm{I}$, which is a pure gamma emitter and is used for pre- and post-therapeutic diagnostics. The advantages of imaging with ${ }^{123} \mathrm{I}$ include a higher quality of whole-body scans, which improves the sensitivity in detecting thyroid remnants. ${ }^{3,4}$

Figure 2A shows the initial ${ }^{131} \mathrm{I}$-planar images of a 74-year-old female with metastatic TC (lung, bone, and intracranial soft-tissue metastases). The level of tumor marker thyroglobulin (Tg) before RAI was $572 \mathrm{ng} / \mathrm{mL}$. After two administrations of RAI (cumulative activity: $14.3 \mathrm{GBq}$ ), the patient was in complete remission with a Tg level of $0.2 \mathrm{ng} / \mathrm{mL}$ (Figure 2B).

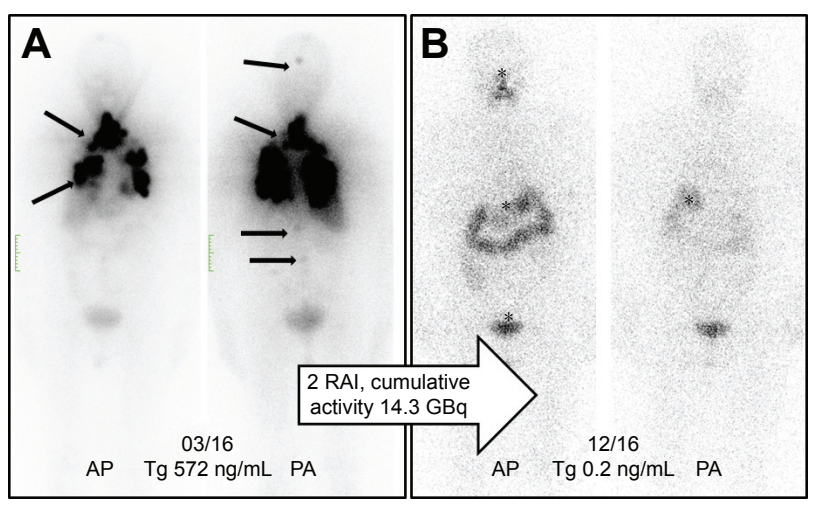

Figure 2 (A) Initial ${ }^{13}$ I-planar images of a 74-year-old female with metastatic thyroid cancer (lung, bone, and intracranial soft-tissue metastases, marked with arrows). The tumor marker thyroglobulin ( $\mathrm{Tg}$ ) before radioiodine therapy (RAI) was $572 \mathrm{ng} / \mathrm{mL}$. (B) After two administrations of RAl (cumulative activity: $14.3 \mathrm{GBq}$ ), the patient was in complete remission with the $\mathrm{Tg}$ at $0.2 \mathrm{ng} / \mathrm{mL}$. The planar images show only a physiological uptake of the radiotracer in the gastrointestinal tract and pharyngeal mucosa (marked with an asterisk).

\section{Diagnostics and therapy with metaiodobenzylguanidine}

Metaiodobenzylguanidine (mIBG), or iobenguane, is a molecule similar to noradrenaline and enters neuroendocrine cells from the sympathetic nervous system, either by endocytosis or passive diffusion before being stored in neurosecretory granules. ${ }^{39}$ Among the used radiolabeled molecules, $\left[{ }^{123} \mathrm{I}\right] \mathrm{I}-\mathrm{mIBG}$ has a lower gamma energy than $\left[{ }^{131} \mathrm{I}\right] \mathrm{I}-\mathrm{mIBG}$ (159 keV vs $360 \mathrm{keV}$ ), which makes it more suitable for planar imaging/SPECT. Furthermore, the pure gamma emitter $\left[{ }^{123} \mathrm{I}\right] \mathrm{I}-\mathrm{mIBG}$ consists of a shorter half-time of 13 hours compared to 8 days for the combined beta and gamma emitter $\left[{ }^{131} \mathrm{I}\right] \mathrm{I}-\mathrm{mIBG}$, leading to a smaller radiation burden. Thus, higher quantities of [ $\left.{ }^{123} \mathrm{I}\right] \mathrm{I}-\mathrm{mIBG}$ can be injected. ${ }^{40}$ Both $\left[{ }^{131} \mathrm{I}\right] \mathrm{I}-\mathrm{mIBG}$ and $\left[{ }^{123} \mathrm{I}\right] \mathrm{I}-\mathrm{mIBG}$ are used in mIBG scintigraphy for the detection of neuroendocrine tumors, such as neuroblastomas, pheochromocytomas, paragangliomas, medullary thyroid carcinomas, and other neuroendocrine neoplasias. ${ }^{41}$ In patients with inoperable or advanced tumors with distant metastases, mIBG imaging plays an essential role in response assessment after therapy and in the evaluation of potential $\left[{ }^{131} \mathrm{I}\right] \mathrm{I}-\mathrm{mIBG}$ therapy. ${ }^{42,43}$ In patients with neuroblastoma and pheochromocytoma, [ $\left.{ }^{123} \mathrm{I}\right] \mathrm{I}-\mathrm{mIBG}$ has high sensitivity (97\% and $\left.94 \%\right)$ and specificity (up to $96 \%$ and $92 \%$ ), respectively. ${ }^{44} 46$ If available, [24I]I-mIBG-PET can be equally used for the planning of mIBG targeted therapy. ${ }^{47,48}$

Targeted therapy with $\left.{ }^{131} \mathrm{I}\right] \mathrm{I}-\mathrm{mIBG}$ presents an encouraging efficacy with tolerable toxicity in relapsed or refractory neuroblastomas with response rates between $20 \%$ and $40 \%$ being used alone or in combination with high-dose 
chemotherapy followed by autologous stem cell transplantation. ${ }^{23-25,49}$ Recently, the NB2004 Trial for Risk Adapted Treatment of Children with Neuroblastoma closed, and further analysis of the usage of mIBG therapy as a first-line therapy is outstanding. ${ }^{23,25}$

\section{Palliation of bone metastases}

Radiolabeled phosphonates have a high bone affinity and can be used for imaging and palliation of painful bone metastases. Depending on the degree of osseous metabolism, the tracer accumulates via adhesion to bones and, preferably, to osteoblastic bone metastases. ${ }^{8}$

Therapy planning requires a bone scintigraphy with technetium-99m-hydroxyethylidene diphosphonate (HEDP) to estimate the metabolism and the extent of the metastases involvement. Bisphosphonate HEDP can be labeled for therapy either with rhenium-186 (beta-emitter, half-life: 89 hours, $1.1 \mathrm{MeV}$ maximal energy, maximal range: $4.6 \mathrm{~mm}$ ) or rhenium-188 (beta-emitter [to 85\%, $2.1 \mathrm{MeV}$ ] and gammaemitter [to $15 \%, 155 \mathrm{keV}$ ], half-life: 16.8 hours, maximal range in soft tissue: $10 \mathrm{~mm}){ }^{50}$

Both agents induce pain relief in $\geq 90 \%$ of patients. ${ }^{51}$ However, rhenium-188 is of particular interest because it can be cost-effectively produced using a tungsten-188/ rhenium-188 generator. The gamma component of the agent allows post-therapeutic imaging of good quality. ${ }^{8}$ Furthermore, patients with prostatic cancer have shown, after two $\left[{ }^{188} \mathrm{Re}\right] \mathrm{Re}-\mathrm{HEDP}$ injections, a significantly higher response rate $(92 \%)$, a prostate-specific antigen (PSA) decline $>50 \%$ (38\%), and a longer PFS ( 7 months) compared to patients who have had a single injection. ${ }^{52,53}$ Biersack et al showed an improved OS of 15.7 months in patients after repeated injections ( $\geq 3$ injections) compared to patients with a single therapy. ${ }^{54}$ Besides transient bone marrow toxicity (thrombocytopenia grade III), the reported toxicity is low to moderate. ${ }^{51}$

New promising radiopharmaceuticals for bone palliation therapy include radiolabeled complexes of zoledronic acid. Zoledronic acid belongs to a new, most potent generation of bisphosphonates with cyclic side chains. The bone affinity of zoledronic acid labeled with scandium-46 or lutetium-177 has shown excellent absorption $\left(98 \%\right.$ for $\left[{ }^{177} \mathrm{Lu}\right] \mathrm{Lu}-z o l e d r o n a t e$ and $82 \%$ for $\left.\left[{ }^{46} \mathrm{Sc}\right] \mathrm{Sc}-z o l e d r o n a t e\right)$, which is much higher than of bisphosphonates labeled with samarium-153 (maximum: 67\%). ${ }^{55}$

\section{Radiolabeled somatostatin analogs}

Neuroendocrine neoplasia (NEN) of the GEP system originates most frequently from the pancreas, jejunum, ileum, cecum, rectum, appendix, and colon. The common characteristic of all GEP-NEN is the compound features of endocrine and nerve cells. ${ }^{56-58}$ Well-differentiated NEN overexpresses somatostatin receptors (SSTRs), especially the SSTR-2 subtype. Thus, SSTRs are theranostic targets in NEN that have been known for almost three decades and have become well established. ${ }^{59-61}$

SSTR imaging is necessary for staging, therapy planning, and follow-up. In the PET diagnostics, there are three routine somatostatin analog (SSA) tracers labelled with gallium-68: DOTA-TATE, DOTA-TOC, and DOTA-NOC. All three tracers bind specifically with SSTRs. ${ }^{62,63}$ Gallium-68-labeled SSTRs have high sensitivity $(82 \%-97 \%)$ and specificity $(80 \%-92 \%)$ in the detection of small primary tumors or metastases of GEP-NEN. ${ }^{64-66}$ Alternatively, a conventional whole-body scintigraphy (planat plus SPECT) or SPECT alone can be performed using indium-111-labeled SSTR, which is available at many institutions. Even if the ${ }^{111} \mathrm{In}$ imaging does not have as good a quality as PET, this method has been shown to be superior to chromogranin A measurements alone for the management of GEP-NET patients and is better than computed tomography or ultrasound. ${ }^{67,68}$

Peptide receptor radionuclide therapy (PRRT) is a systemic therapy in patients with advanced metastatic NEN. PRRT requires a good tumor uptake in the SSTR imaging. For therapeutic purposes, the peptides DOTA-TATE and DOTA-TOC can be labeled with either ${ }^{90} \mathrm{Y}$ or ${ }^{177} \mathrm{Lu}$. Because of the renal excretion and the proximal tubular reabsorption of these tracers, the kidneys are one of the primary limiting organs for this therapy. ${ }^{69}$ Due to the smaller range (2 mm) and lower energy, ${ }^{177} \mathrm{Lu}$ is less nephrotoxic than ${ }^{90} \mathrm{Y}$ (range maximum: $11 \mathrm{~mm}$, pure beta emitter, higher energy). ${ }^{177} \mathrm{Lu}$ is also less hematotoxic. ${ }^{70}$ This allows for the performance of several PRRT cycles without any relevant toxicity. Furthermore, the overall survival is not significantly different between the therapies. For that reason, $\left[{ }^{177} \mathrm{Lu}\right]$ Lu-DOTA-TATE and DOTA-TOC are, in many centers, the preferred agents for NEN therapy. ${ }^{10,11,71,72}$

PRRT has been increasingly gaining attention. The first randomized controlled phase III study, NETTER-1 (started 2012), compared the standard therapy of Sandostatin ${ }^{\circledR}$ LAR (somatostatin analog) with PRRT in patients with midgut NEN. The study showed a significant clinical benefit from the therapy, achieving a prolonged progression-free survival (median not reached, approximately 40 months, $p<0.001$ ), an overall response of $18 \%$, and a presumably longer overall survival (median not reached, $p=0.004) .{ }^{11}$

Figure 3 represents the image of a male patient with a neuroendocrine tumor (unknown origin), with a recurrence of 

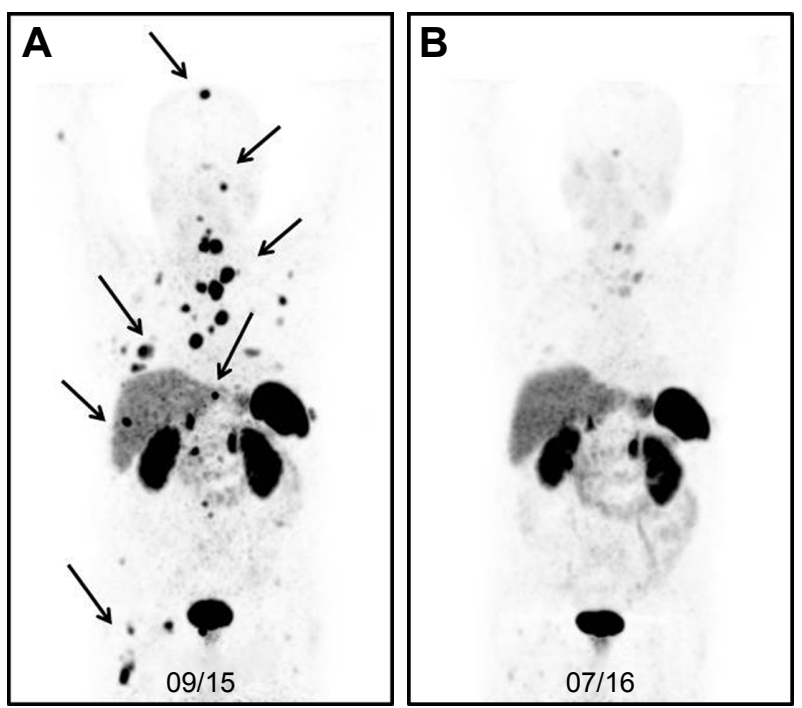

Figure 3 (A) $\left[{ }^{68} \mathrm{Ga}\right] \mathrm{Ga}$-DOTA-TOC-image* of a male patient with a neuroendocrine tumor (unknown origin) 23 months after the baseline PRRT (three cycles, cumulative activity: $19.6 \mathrm{GBq}$ ). The patient had a recurrence of the disease with multiple metastases in the bone, lung, liver, and lymph nodes (marked with arrows). (B) After another course of PRRT (three cycles, cumulative: $43.4 \mathrm{GBq}$ ), the PET images showed a partial response.

Note: *Maximum-intensity projection (MIP) PET image is a visualization technique that provides an initial overview of the case.

Abbreviations: PET, positron emission tomography; PRRT, peptide receptor radionuclide therapy.

the disease nearly 2 years after the baseline PRRT. After a salvage therapy of PRRT, the patient had a partial response.

\section{Radiolabeled PSMA-ligands}

$\mathrm{PC}$ is the most common cancer in men in Western countries. ${ }^{73}$ Hormone- and chemotherapy-refractory patients with metastatic PC have a poor prognosis. ${ }^{8,74,75}$ The main cause of death in these patients is progression to the androgenindependent stage. ${ }^{8}$

PC cells overexpress prostate-specific membrane antigen (PSMA) on the cell surface. ${ }^{76-79}$ There are several available radiopharmaceuticals that target PSMA including $\left[{ }^{68} \mathrm{Ga}\right] \mathrm{Ga}-$ PSMA-HBED-CC (also known as $\left[{ }^{68} \mathrm{Ga}\right] \mathrm{Ga}-\mathrm{PSMA}-11$ $[\mathrm{PET}])$, a monoclonal antibody (mAb) $\left[{ }^{177} \mathrm{Lu}\right] \mathrm{Lu} /\left[{ }^{90} \mathrm{Y}\right] \mathrm{Y}-\mathrm{J} 591$ (therapy), $\left[{ }^{123} \mathrm{I}\right] \mathrm{I}-\mathrm{MIP}-1072$ (planar/SPECT), [ $\left.{ }^{131} \mathrm{I}\right] \mathrm{I}-\mathrm{MIP}-1095$ (therapy), and the theranostic agents PSMA-I\&T and DKFZPSMA-617 (PSMA-617), which are labeled with ${ }^{68} \mathrm{Ga}$ for PET or with ${ }^{177} \mathrm{Lu}$ for therapy.

The specificity of the two commercially available PETtracers, $\left[{ }^{68} \mathrm{Ga}\right] \mathrm{Ga}-\mathrm{PSMA}-617$ and $\left[{ }^{68} \mathrm{Ga}\right] \mathrm{Ga}-\mathrm{PSMA}-11$, is similar $-99 \%$ and $100 \%$, respectively ${ }^{80-82}$ However, due to slower kinetics, PSMA-617 was suggested for labeling with the long-half-life Lutetium-177 for therapy and, therefore, there is sparse systematic evaluation of $\left[{ }^{68} \mathrm{Ga}\right] \mathrm{Ga}-\mathrm{PSMA}-617$ for diagnostics. ${ }^{83}$ The high kidney uptake of PSMA-11 in the kidneys makes it unsuitable for therapy and does not fit the definition "theranostics." 84 Still, it is at issue if molecules with affinity to identical target structures might already present a "theranostic surrogate" even if more than the isotope differs between the diagnostics and the therapeutics.

The latest studies have shown that treatment with $\left[{ }^{177} \mathrm{Lu}\right]$ Lu-PSMA-617 is effective and well tolerated. In fact, nearly $70 \%$ of patients have benefited from this therapy. ${ }^{13,28,85-90}$ Dosimetry studies have shown that the most critical organs are the kidneys, with a maximum kidney radiation dose of $0.88 \mathrm{~Gy} / \mathrm{GBq}$ for $\left[{ }^{177} \mathrm{Lu}\right] \mathrm{Lu}-\mathrm{PSMA}-617$ and $0.93 \mathrm{~Gy} / \mathrm{GBq}$ for $\left[{ }^{177} \mathrm{Lu}\right] \mathrm{Lu}-\mathrm{PSMA}-\mathrm{I} \& \mathrm{~T} .{ }^{91,92}$ Okamoto et al stated that a cumulative activity of $40 \mathrm{GBq}\left[{ }^{177} \mathrm{Lu}\right] \mathrm{Lu}-\mathrm{PSMA}-\mathrm{I} \& \mathrm{~T}$ could be safely applied in patients. ${ }^{91}$ Furthermore, $\left[{ }^{177} \mathrm{Lu}\right] \mathrm{Lu}-\mathrm{PSMA}-$ 617 has been shown to produce no relevant increase in renal toxicity in the salvage setting or in patients with kidney radiation doses $>19$ Gy. ${ }^{14}$

Figure 4A shows the pre-therapeutic $\left[{ }^{68} \mathrm{Ga}\right] \mathrm{Ga}-\mathrm{PSMA}-11$ images of a patient with multiple lymph node, peritoneal, and bone metastases (arrows), and a history of chemotherapy (first and second line), enzalutamide, and abiraterone. After three cycles of $\left[{ }^{177} \mathrm{Lu}\right] \mathrm{Lu}-\mathrm{PSMA}-617$, the follow-up images show a very good response with a substantial PSA decline (Figure 4B).

\section{Melanin targeting in patients with metastatic melanoma}

A promising approach in patients with metastatic melanoma is the specific targeting of melanin. The newly developed theranostic agents include $\left[{ }^{123} \mathrm{I}\right] \mathrm{I}-/\left[{ }^{131} \mathrm{I}\right] \mathrm{I}-\mathrm{BA} 52$ and $\left[{ }^{18} \mathrm{~F}\right] \mathrm{F}-/$ $\left[{ }^{131} \mathrm{I}\right] \mathrm{F}-\mathrm{ICF} 15002$, which may play a considerable role in the future.

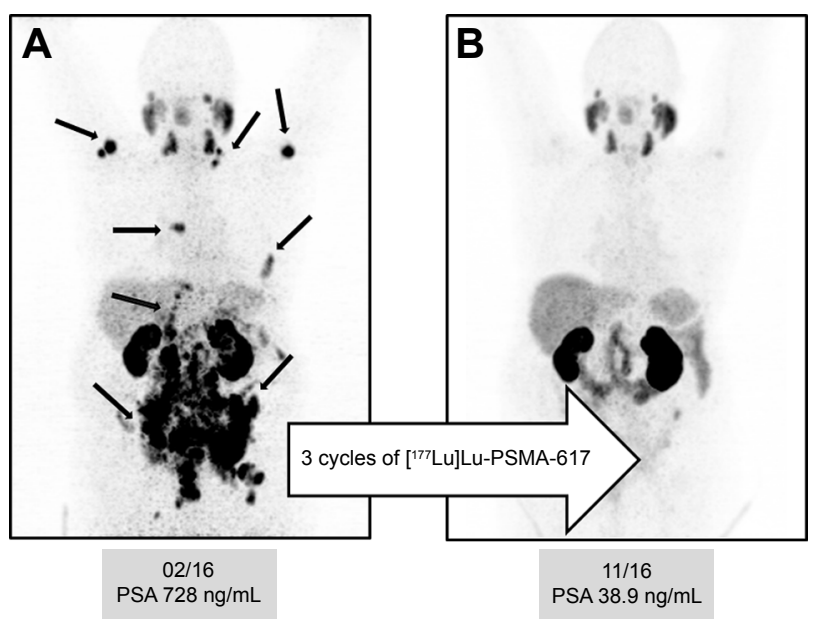

Figure 4 (A) Pre-therapeutic $\left[{ }^{68} \mathrm{G}\right.$ ] Ga-PSMA-I I images* of a patient with multiple lymph node, peritoneal, and bone metastases (arrows), and history of chemotherapy (first and second line) with enzalutamide and abiraterone. (B) After three cycles of [ $\left.{ }^{177} \mathrm{Lu}\right]$ Lu-PSMA-617, the follow-up images showed a very good response with a substantial PSA decline.

Note: *Maximum-intensity projection (MIP) PET image is a visualization technique that provides an initial overview of the case.

Abbreviations: PET, positron emission tomography; PSA, prostate-specific antigen. 
BA52 is a melanin-binding benzamide. Labeled with ${ }^{123} \mathrm{I}$, it shows a specific binding of the pigmented metastases in planar imaging/SPECT and can help select patients who would probably benefit from the therapy. In a pilot study, $\left[{ }^{131} \mathrm{I}\right] \mathrm{I}-\mathrm{BA} 52$ was effective in three of five patients who were treated with more than $4.3 \mathrm{GBq} .{ }^{29}$

ICF15002 is an arylcarboxamide derivative and, as a small molecule, can passively enter the cell and bind to melanin. The PET tracer is radiolabeled with ${ }^{18} \mathrm{~F}$ and $\left[{ }^{131} \mathrm{I}\right] \mathrm{I}-\mathrm{ICF} 15002$ is designed for the therapy. However, both tracers are still in the preclinical phase of their studies. One major problem may be the absorbed dose in melanin-rich tissues, such as skin, dark eyes, and the brain. For instance, in a murine model, there was a $30 \%$ decrease of the retinal thickness after two cycles of [ $\left.{ }^{131} \mathrm{I}\right] \mathrm{I}-\mathrm{ICF} 15002 .{ }^{93}$

\section{Conclusion}

In nuclear medicine, theranostics combine diagnostic imaging and therapy with the same, but differently radiolabeled, molecule, or the same agent in different dosages. The visualization of potential targets can help predict if a patient would benefit from a particular treatment. In properly preselected patients, targeted nuclear therapies have proven to be effective with a favorable safety profile. To conclude, the combination of targeted cancer imaging and therapy is a considerable contribution to personalized medicine and may play an increasingly important role in the future.

\section{Disclosure}

The authors report no conflicts of interest in this work.

\section{References}

1. Gridelli C. Does chemotherapy have a role as palliative therapy for unfit or elderly patients with non-small-cell lung cancer? Lung Cancer. 2002;38(Suppl 2):S45-S50.

2. Richardson JL, Marks G, Levine A. The influence of symptoms of disease and side effects of treatment on compliance with cancer therapy. J Clin Oncol. 1988;6(11):1746-1752.

3. Gerard SK, Cavalieri RR. I-123 diagnostic thyroid tumor whole-body scanning with imaging at 6, 24, and 48 hours. Clin Nucl Med. 2002; 27(1): $1-8$.

4. Alzahrani AS, AlShaikh O, Tuli M, Al-Sugair A, Alamawi R, Al-Rasheed MM. Diagnostic value of recombinant human thyrotropin-stimulated ${ }^{123}$ I whole-body scintigraphy in the follow-up of patients with differentiated thyroid cancer. Clin Nucl Med. 2012;37(3):229-234.

5. Walrand S, Hesse M, Renaud L, Jamar F. The impact of image reconstruction bias on $\mathrm{PET} / \mathrm{CT}^{90} \mathrm{Y}$ dosimetry after radioembolization. $\mathrm{J} \mathrm{Nucl}$ Med. 2015;56(3):494-495.

6. Müller C, Zhernosekov K, Köster U, et al. A unique matched quadruplet of terbium radioisotopes for PET and SPECT and for alpha- and beta-radionuclide therapy: an in vivo proof-of-concept study with a new receptor-targeted folate derivative. J Nucl Med. 2012;53(12):1951-1959.

7. Seidlin SM, Siegel E, Yalow AA, Melamed S. Acute myeloid leukemia following prolonged iodine-131 therapy for metastatic thyroid carcinoma. Science. 1956;123(3201):800-801.
8. Ahmadzadehfar H. Targeted therapy for metastatic prostate cancer with radionuclides. In: Mohan R, editor. Prostate Cancer - Leadingedge Diagnostic Procedures and Treatments. InTech; 2016. DOI: 10.5772/64016. Available from: https://www.intechopen.com/books/ prostate-cancer-leading-edge-diagnostic-procedures-and-treatments/ targeted-therapy-for-metastatic-prostate-cancer-with-radionuclides. Accessed August 23, 2017.

9. Baum RP, Kulkarni HR. THERANOSTICS: from molecular imaging using Ga-68 labeled tracers and PET/CT to personalized radionuclide therapy - the Bad Berka experience. Theranostics. 2012;2(5): 437-447.

10. Kwekkeboom DJ, de Herder WW, Kam BL, et al. Treatment with the radiolabeled somatostatin analog [177 Lu-DOTA 0, Tyr3] octreotate: toxicity, efficacy, and survival. J Clin Oncol. 2008;26(13): 2124-2130.

11. Strosberg J, El-Haddad G, Wolin E, et al; NETTER-1 Trial Investigators. Phase 3 trial of $177 \mathrm{Lu}$-dotatate for midgut neuroendocrine tumors. N Engl J Med. 2017;376(2):125-135.

12. Yordanova A, Mayer K, Brossart P, et al. Safety of multiple repeated cycles of $177 \mathrm{Lu}$-octreotate in patients with recurrent neuroendocrine tumour. Eur J Nucl Med Mol Imaging. 2017;44(7):1207-1214.

13. Ahmadzadehfar H, Eppard E, Kurpig S, et al. Therapeutic response and side effects of repeated radioligand therapy with 177Lu-PSMADKFZ-617 of castrate-resistant metastatic prostate cancer. Oncotarget. 2016;7(11):12477-12488.

14. Yordanova A, Becker A, Eppard E, et al. The impact of repeated cycles of radioligand therapy using [177Lu]Lu-PSMA-617 on renal function in patients with hormone refractory metastatic prostate cancer. Eur $J$ Nucl Med Mol Imaging. 2017;44(9):1473-1479.

15. Holman BL, Tumeh SS. Single-photon emission computed tomography (SPECT): applications and potential. JAMA. 1990;263(4): 561-564.

16. Eckelman WC, Gibson RE. The design of site-directed radiopharmaceuticals for use in drug discovery. In: Nuclear Imaging In Drug Discovery, Development, and Approval: Springer; 1993:113-134.

17. Kramer-Marek G, Capala J. The role of nuclear medicine in modern therapy of cancer. Tumour Biol. 2012;33(3):629-640.

18. Pillai MR, Chakraborty S, Das T, Venkatesh M, Ramamoorthy N. Production logistics of $177 \mathrm{Lu}$ for radionuclide therapy. Appl Radiat Isot. 2003;59(2-3):109-118.

19. Ahmadzadehfar H, Biersack HJ, Ezziddin S. Radioembolization of liver tumors with yttrium-90 microspheres. Semin Nucl Med. 2010; 40(2):105-121.

20. Teunissen JJM, Kwekkeboom DJ, de Jong M, Esser JP, Valkema R, Krenning EP. Endocrine tumours of the gastrointestinal tract. Peptide receptor radionuclide therapy. Best Pract Res Clin Gastroenterol. 2005;19(4):595-616.

21. Hertz B. Dr. Saul Hertz (1905-1950) discovers the medical uses of radioactive iodine: the first targeted cancer therapy. In: Ahmadzadehfar $\mathrm{H}$, editor. Thyroid Cancer-Advances in Diagnosis and Therapy. Intechopen; 2016:1.

22. Klingebiel T, Bader P, Bares R, et al. Treatment of neuroblastoma stage 4 with 131I-meta-iodo-benzylguanidine, high-dose chemotherapy and immunotherapy. A pilot study. Eur J Cancer. 1998;34(9): 1398-1402.

23. French S, DuBois SG, Horn B, et al. 131I-MIBG followed by consolidation with busulfan, melphalan and autologous stem cell transplantation for refractory neuroblastoma. Pediatr Blood Cancer. 2013; 60(5):879-884.

24. Matthay KK, Yanik G, Messina J, et al. Phase II study on the effect of disease sites, age, and prior therapy on response to iodine-131metaiodobenzylguanidine therapy in refractory neuroblastoma. $J$ Clin Oncol. 2007;25(9):1054-1060.

25. Yanik GA, Villablanca JG, Maris JM, et al. 131I-metaiodobenzylguanidine with intensive chemotherapy and autologous stem cell transplantation for high-risk neuroblastoma. A new approaches to neuroblastoma therapy (NANT) phase II study. Biol Blood Marrow Transplant. 2015;21(4):673-681. 
26. Stoelben E, Yordanova A, Gossmann A, et al. [Carcinoids of the lungs] Best Practice Onkologie. 2016;11(5):22-28. German [with English abstract].

27. Yordanova A, Ahmadzadehfar H, Gonzalez-Carmona M, et al. A stepby-step clinical approach for the management of neuroendocrine tumours. Horm Metab Res. 2017;49(2):77-85.

28. Ferdinandus J, Eppard E, Gartner F, et al. Predictors of response to radioligand therapy of metastatic castrate-resistant prostate cancer with 177Lu-PSMA-617. J Nucl Med. 2017;58(2):312-319.

29. Mier W, Kratochwil C, Hassel JC, et al. Radiopharmaceutical therapy of patients with metastasized melanoma with the melanin-binding benzamide 131I-BA52. J Nucl Med. 2014;55(1):9-14.

30. Zhang J, Lazar MA. The mechanism of action of thyroid hormones. Annu Rev Physiol. 2000;62(1):439-466.

31. Porterfield SP, Hendrich CE. The role of thyroid hormones in prenatal and neonatal neurological development - current perspectives. Endocr Rev. 1993;14(1):94-106.

32. Bauer FK, Barrett TF, Cassen BC. Scintigrams of the thyroid gland; the diagnosis of morphologic abnormalities with I131. Calif Med. 1952;77(6):380-382.

33. Hänscheid H, Lassmann M. Dosimetrie bei der Radioiodtherapie benigner und maligner Schilddrüsenerkrankungen. Nuklearmediziner. 2012;35(01):30-36.

34. Hertz B, Schuller K. Saul Hertz, MD (1905-1950): a pioneer in the use of radioactive iodine. Endocrine Pract. 2010;16(4):713-715.

35. Hertz S, Roberts A. Radioactive iodine as an indicator in thyroid physiology: V. The use of radioactive iodine in the differential diagnosis of two types of Graves' disease. J Clin Invest. 1942;21(1):31-32.

36. Seidlin SM, Rossman I, Oshry E, Siegel E. Radioiodine therapy of metastases from carcinoma of the thyroid; a 6-year progress report. J Clin Endocrinol Metab. 1949;9(11):1122-1137.

37. Seidlin SM. Radioiodine in the treatment of metastatic thyroid carcinoma. Med Clin North Am. 1952;36(3):663-680.

38. Luster M, Clarke SE, Dietlein M, et al; European Association of Nuclear Medicine (EANM). Guidelines for radioiodine therapy of differentiated thyroid cancer. Eur J Nucl Med Mol Imaging. 2008;35(10): 1941-1959.

39. Nakajo M, Shapiro B, Copp J, et al. The normal and abnormal distribution of the adrenomedullary imaging agent $\mathrm{m}$-[I-131]iodobenzylguanidine [I-131 MIBG] in man: evaluation by scintigraphy. J Nucl Med. 1983;24(8):672-682.

40. Shapiro B, Gross MD. Radiochemistry, biochemistry, and kinetics of 131I-metaiodobenzylguanidine (MIBG) and 123I-MIBG: clinical implications of the use of 123I-MIBG. Med Pediatr Oncol. 1987;15(4): $170-177$.

41. Bombardieri E, Giammarile F, Aktolun C, et al; European Association for Nuclear Medicine. 131I/123I-metaiodobenzylguanidine (mIBG) scintigraphy: procedure guidelines for tumour imaging. Eur J Nucl Med Mol Imaging. 2010;37(12):2436-2446.

42. Decarolis B, Schneider C, Hero B, et al. Iodine-123 metaiodobenzylguanidine scintigraphy scoring allows prediction of outcome in patients with stage 4 neuroblastoma: results of the Cologne interscore comparison study. J Clin Oncol. 2013;31(7):944-951.

43. Schmidt M, Simon T, Hero B, Schicha H, Berthold F. The prognostic impact of functional imaging with (123)I-mIBG in patients with stage 4 neuroblastoma $>1$ year of age on a high-risk treatment protocol: results of the German Neuroblastoma Trial NB97. Eur J Cancer. 2008;44(11):1552-1558

44. Jacobson AF, Deng H, Lombard J, Lessig HJ, Black RR. 123 I-metaiodobenzylguanidine scintigraphy for the detection of neuroblastoma and pheochromocytoma: results of a meta-analysis. J Clin Endocrinol Metab. 2010;95(6):2596-2606.

45. Rufini V, Fisher GA, Shulkin BL, Sisson JC, Shapiro B. Iodine123-MIBG imaging of neuroblastoma: utility of SPECT and delayed imaging. J Nucl Med. 1996;37(9):1464-1468.

46. Leung A, Shapiro B, Hattner R, et al. Specificity of radioiodinated MIBG for neural crest tumors in childhood. J Nucl Med. 1997;38(9): $1352-1357$.
47. Ott RJ, Tait D, Flower MA, Babich JW, Lambrecht RM. Treatment planning for 131I-mIBG radiotherapy of neural crest tumours using 124I-mIBG positron emission tomography. Br J Radiol. 1992;65(777): $787-791$.

48. Huang SY, Bolch WE, Lee C, et al. Patient-specific dosimetry using pretherapy $\left[{ }^{124} \mathrm{I}\right] \mathrm{m}$-iodobenzylguanidine $\left(\left[{ }^{124} \mathrm{I}\right] \mathrm{mIBG}\right)$ dynamic PET/ CT imaging before $\left[{ }^{131} \mathrm{I}\right] \mathrm{mIBG}$ targeted radionuclide therapy for neuroblastoma. Mol Imaging Biol. 2015;17(2):284-294.

49. Zhou MJ, Doral MY, DuBois SG, Villablanca JG, Yanik GA, Matthay KK. Different outcomes for relapsed versus refractory neuroblastoma after therapy with (131)I-metaiodobenzylguanidine ((131)I-MIBG). Eur J Cancer. 2015;51(16):2465-2472.

50. Palmedo H. Radionuclide therapy of bone metastases. In: Biersack HJ, Freeman LM, editors. Clinical Nuclear Medicine. Berlin, Heidelberg: Springer Berlin Heidelberg; 2007:433-442.

51. Liepe K, Kotzerke J. A comparative study of 188Re-HEDP, 186ReHEDP, 153Sm-EDTMP and 89Sr in the treatment of painful skeletal metastases. Nucl Med Commun. 2007;28(8):623-630.

52. Palmedo H, Manka-Waluch A, Albers P, et al. Repeated bonetargeted therapy for hormone-refractory prostate carcinoma: tandomized phase II trial with the new, high-energy radiopharmaceutical rhenium-188 hydroxyethylidenediphosphonate. J Clin Oncol. 2003; 21(15):2869-2875.

53. Palmedo H, Guhlke S, Bender H, et al. Dose escalation study with rhenium-188 hydroxyethylidene diphosphonate in prostate cancer patients with osseous metastases. Eur J Nucl Med. 2000;27(2):123-130.

54. Biersack HJ, Palmedo H, Andris A, et al. Palliation and survival after repeated (188)Re-HEDP therapy of hormone-refractory bone metastases of prostate cancer: a retrospective analysis. J Nucl Med. 2011; 52(11):1721-1726.

55. Majkowska A, Neves M, Antunes I, Bilewicz A. Complexes of low energy beta emitters $47 \mathrm{Sc}$ and $177 \mathrm{Lu}$ with zoledronic acid for bone pain therapy. Appl Radiat Isot. 2009;67(1):11-13.

56. Kloppel G. Classification and pathology of gastroenteropancreatic neuroendocrine neoplasms. Endocr Relat Cancer. 2011;18(Suppl 1): S1-S16.

57. Kloppel G, Rindi G, Anlauf M, Perren A, Komminoth P. Site-specific biology and pathology of gastroenteropancreatic neuroendocrine tumors. Virchows Arch. 2007;451(Suppl 1):S9-S27.

58. Rindi G, Kloppel G, Couvelard A, et al. TNM staging of midgut and hindgut (neuro) endocrine tumors: a consensus proposal including a grading system. Virchows Arch. 2007;451(4):757-762.

59. Lamberts SW, Bakker WH, Reubi JC, Krenning EP. Treatment with Sandostatin and in vivo localization of tumors with radiolabeled somatostatin analogs. Metabolism. 1990;39(9 Suppl 2):152-155.

60. Lamberts SW, Reubi JC, Bakker WH, Krenning EP. Somatostatin receptor imaging with 123I-Tyr3-Octreotide. Z Gastroenterol. 1990; 28(Suppl 2):20-21.

61. Krenning EP, Bakker WH, Breeman WA, et al. Localisation of endocrine-related tumours with radioiodinated analogue of somatostatin. Lancet. 1989;1(8632):242-244.

62. Poeppel TD, Binse I, Petersenn S, et al. 68Ga-DOTATOC versus $68 \mathrm{Ga}-\mathrm{DOTATATE} \mathrm{PET} / \mathrm{CT}$ in functional imaging of neuroendocrine tumors. J Nucl Med. 2011;52(12):1864-1870.

63. Wild D, Schmitt JS, Ginj M, et al. DOTA-NOC, a high-affinity ligand of somatostatin receptor subtypes 2, 3 and 5 for labelling with various radiometals. Eur J Nucl Med Mol Imaging. 2003;30(10):1338-1347.

64. Gabriel M, Decristoforo C, Kendler D, et al. 68Ga-DOTA-Tyr3octreotide PET in neuroendocrine tumors: comparison with somatostatin receptor scintigraphy and CT. J Nucl Med. 2007;48(4):508-518.

65. Haug A, Auernhammer CJ, Wangler B, et al. Intraindividual comparison of $68 \mathrm{Ga}$-DOTA-TATE and 18F-DOPA PET in patients with well-differentiated metastatic neuroendocrine tumours. Eur J Nucl Med Mol Imaging. 2009;36(5):765-770.

66. Kayani I, Bomanji JB, Groves A, et al. Functional imaging of neuroendocrine tumors with combined PET/CT using 68Ga-DOTATATE (DOTA-DPhe1, Tyr3-octreotate) and 18F-FDG. Cancer. 2008;112(11): 2447-2455. 
67. Chiti A, Fanti S, Savelli G, et al. Comparison of somatostatin receptor imaging, computed tomography and ultrasound in the clinical management of neuroendocrine gastro-entero-pancreatic tumours. Eur J Nucl Med. 1998;25(10):1396-1403.

68. Cimitan M, Buonadonna A, Cannizzaro R, et al. Somatostatin receptor scintigraphy versus chromogranin A assay in the management of patients with neuroendocrine tumors of different types: clinical role. Ann Oncol. 2003;14(7):1135-1141.

69. Sabet A, Ezziddin K, Pape UF, et al. Accurate assessment of long-term nephrotoxicity after peptide receptor radionuclide therapy with (177) Lu-octreotate. Eur J Nucl Med Mol Imaging. 2014;41(3):505-510.

70. Romer A, Seiler D, Marincek N, et al. Somatostatin-based radiopeptide therapy with [177Lu-DOTA]-TOC versus [90Y-DOTA]-TOC in neuroendocrine tumours. Eur J Nucl Med Mol Imaging. 2014; 41(2):214-222.

71. Wong FC, Kim EE. Therapeutic applications of radiopharmaceuticals. In: Kim EE, editor. Handbook of Nuclear Medicine and Molecular Imaging: Principles and Clinical Applications. New Jersey: World Scientific; 2012:401.

72. Cwikla JB, Sankowski A, Seklecka N, et al. Efficacy of radionuclide treatment DOTATATE Y-90 in patients with progressive metastatic gastroenteropancreatic neuroendocrine carcinomas (GEP-NETs): a phase II study. Ann Oncol. 2010;21(4):787-794.

73. Ferlay J, Soerjomataram I, Dikshit R, et al. Cancer incidence and mortality worldwide: sources, methods and major patterns in GLOBOCAN 2012. Int J Cancer. 2015;136(5):E359-E386.

74. Sonpavde G, Periman PO, Bernold D, et al. Sunitinib malate for metastatic castration-resistant prostate cancer following docetaxel-based chemotherapy. Ann Oncol. 2010;21(2):319-324.

75. Tolcher AW, Quinn DI, Ferrari A, et al. A phase II study of YM155, a novel small-molecule suppressor of survivin, in castration-resistant taxane-pretreated prostate cancer. Ann Oncol. 2012;23(4):968-973.

76. Ghosh A, Heston WDW. Tumor target prostate specific membrane antigen (PSMA) and its regulation in prostate cancer. J Cell Biochem. 2004;91(3):528-539.

77. Mhawech-Fauceglia P, Zhang S, Terracciano L, et al. Prostate-specific membrane antigen (PSMA) protein expression in normal and neoplastic tissues and its sensitivity and specificity in prostate adenocarcinoma: an immunohistochemical study using mutiple tumour tissue microarray technique. Histopathology. 2007;50(4):472-483.

78. Santoni M, Scarpelli M, Mazzucchelli R, et al. Targeting prostatespecific membrane antigen for personalized therapies in prostate cancer: morphologic and molecular backgrounds and future promises. J Biol Regul Homeost Agents. 2014;28(4):555-563.

79. Silver DA, Pellicer I, Fair WR, Heston WD, Cordon-Cardo C. Prostatespecific membrane antigen expression in normal and malignant human tissues. Clin Cancer Res. 1997;3(1):81-85.

80. Afshar-Oromieh A, Avtzi E, Giesel FL, et al. The diagnostic value of PET/CT imaging with the (68)Ga-labelled PSMA ligand HBED-CC in the diagnosis of recurrent prostate cancer. Eur J Nucl Med Mol Imaging. 2015;42(2):197-209.

OncoTargets and Therapy

\section{Publish your work in this journal}

OncoTargets and Therapy is an international, peer-reviewed, open access journal focusing on the pathological basis of all cancers, potential targets for therapy and treatment protocols employed to improve the management of cancer patients. The journal also focuses on the impact of management programs and new therapeutic agents and protocols on

Submit your manuscript here: http://www.dovepress.com/oncotargets-and-therapy-journal
81. Hijazi S, Meller B, Leitsmann C, et al. Pelvic lymph node dissection for nodal oligometastatic prostate cancer detected by 68Ga-PSMA-positron emission tomography/computerized tomography. Prostate. 2015; 75(16):1934-1940.

82. Perera M, Papa N, Christidis D, et al. Sensitivity, specificity, and predictors of positive $68 \mathrm{Ga}$-prostate-specific membrane antigen positron emission tomography in advanced prostate cancer: a systematic review and meta-analysis. Eur Urol. 2016;70(6):926-937.

83. Afshar-Oromieh A, Hetzheim H, Kratochwil C, et al. The theranostic PSMA ligand PSMA-617 in the diagnosis of prostate cancer by PET/ CT: biodistribution in humans, radiation dosimetry, and first evaluation of tumor lesions. J Nucl Med. 2015;56(11):1697-1705.

84. Afshar-Oromieh A, Hetzheim H, Kubler W, et al. Radiation dosimetry of (68)Ga-PSMA-11 (HBED-CC) and preliminary evaluation of optimal imaging timing. Eur J Nucl Med Mol Imaging. 2016;43(9): 1611-1620.

85. Rahbar K, Ahmadzadehfar H, Kratochwil C, et al. German multicenter study investigating ${ }^{177} \mathrm{Lu}$-PSMA-617 radioligand therapy in advanced prostate cancer patients. J Nucl Med. 2017;58:85-90.

86. Rahbar K, Bode A, Weckesser M, et al. Radioligand therapy with 177Lu-PSMA-617 as a novel therapeutic option in patients with metastatic castration resistant prostate cancer. Clin Nucl Med. 2016;41(7): 522-528.

87. Rahbar K, Schmidt M, Heinzel A, et al. Response and tolerability of a single dose of 177Lu-PSMA-617 in patients with metastatic castrationresistant prostate cancer: a multicenter retrospective analysis. $\mathrm{J} \mathrm{Nucl}$ Med. 2016;57(9):1334-1338.

88. Ahmadzadehfar H, Rahbar K, Kurpig S, et al. Early side effects and first results of radioligand therapy with (177)Lu-DKFZ-617 PSMA of castrate-resistant metastatic prostate cancer: a two-centre study. EJNMMI Res. 2015;5(1):114.

89. Becker A, Eppard E, Kuerpig S, et al. Nephro- and hepatotoxicity after radioligand therapy of metastatic castrate-resistant prostate cancer with 177Lu-PSMA-617. J Nucl Med. 2016;57(Suppl 2):1430.

90. Zimbelmann S, Eppard E, Hauser S, et al. Hematotoxicity after radioligand therapy of metastatic castrate-resistant prostate cancer with 177Lu-PSMA-617. J Nucl Med. 2016;57(Suppl 2):1429.

91. Okamoto S, Thieme A, Allmann J, et al. Radiation dosimetry for $177 \mathrm{Lu}-$ PSMA I\&T in metastatic castration-resistant prostate cancer: absorbed dose in normal organs and tumor lesions. J Nucl Med. 2017;58(3): $445-450$.

92. Kabasakal L, AbuQbeitah M, Aygun A, et al. Pre-therapeutic dosimetry of normal organs and tissues of (177)Lu-PSMA-617 prostate-specific membrane antigen (PSMA) inhibitor in patients with castration-resistant prostate cancer. Eur J Nucl Med Mol Imaging. 2015;42(13):1976-1983.

93. Rbah-Vidal L, Vidal A, Billaud EMF, et al. Theranostic approach for metastatic pigmented melanoma using ICF15002, a multimodal radiotracer for both PET imaging and targeted radionuclide therapy. Neoplasia. 2017;19(1):17-27. patient perspectives such as quality of life, adherence and satisfaction. The manuscript management system is completely online and includes a very quick and fair peer-review system, which is all easy to use. Visit http://www.dovepress.com/testimonials.php to read real quotes from published authors. 